\title{
Auxin Modulated Initiation of Lateral Roots Is Linked to Pericycle Cell Length in Maize
}

\author{
M. Victoria Alarcón ${ }^{1,2 \dagger \neq}$, Julio Salguero ${ }^{3 \uparrow}$ and Pedro G. Lloret ${ }^{2 *}$
}

'Departamento de Hortofruticultura, Instituto de Investigaciones Agrarias "La Orden-Valdesequera", CICYTEX, Junta de Extremadura, Badajoz, Spain, ${ }^{2}$ Departamento de Anatomía, Biología Celular y Zoología, Facultad de Ciencias, Universidad de Extremadura, Badajoz, Spain, ${ }^{3}$ Departamento de Biología Vegetal, Ecología y Ciencias de la Tierra, Universidad de Extremadura, Badajoz, Spain

\section{OPEN ACCESS}

Edited by:

Joseph G. Dubrovsky, National Autonomous University

of Mexico, Mexico

Reviewed by: Peng Yu,

Universität Bonn, Germany

Aleš Soukup,

Charles University, Czechia

*Correspondence:

Pedro G. Lloret

plloret@unex.es

orcid.org/0000-0001-5051-8463

${ }^{\dagger}$ These authors have contributed equally to this work

$\mp$ M. Victoria Alarcón orcid.org/0000-0003-3874-0226

$\checkmark$ Julio Salguero orcid.org/0000-0002-6348-3965

Specialty section:

This article was submitted to Plant Development and EvoDevo,

a section of the journal

Frontiers in Plant Science

Received: 11 July 2018

Accepted: 07 January 2019

Published: 24 January 2019

Citation:

Alarcón MV, Salguero J and Lloret PG (2019) Auxin Modulated Initiation of Lateral Roots Is Linked to Pericycle Cell Length in Maize.

Front. Plant Sci. 10:11.

doi: 10.3389/fpls.2019.00011
Auxin is essential for the regulation of root system architecture by controlling primary root elongation and lateral root (LR) formation. Exogenous auxin has been reported to inhibit primary root elongation and promote the formation of LRs. In this study, LR formation in the Zea mays primary root was quantitatively evaluated after exogenous auxin treatment by comparing the effects of auxin on two selected zones elongated either before or after auxin application. We determined two main variables in both zones: the LR density per unit of root length (LRD), and the mean phloem pericycle cell length. The total number of phloem pericycle cells (PPCs) per unit of root length was then calculated. Considering that each LR primordium is initiated from four founder cells (FCs), the percentage of PPCs (\%PPC) that behave as FCs in a specific root zone was estimated by dividing the number of pericycle cells by four times the LRD. This index was utilized to describe $L R$ initiation. Root zones elongated in the presence of a synthetic auxin (1-naphthalene acetic acid, NAA) at low concentrations $(0.01 \mu \mathrm{M})$ showed reduced cell length and increased LRD. However, a high concentration of NAA $(0.1 \mu \mathrm{M})$ strongly reduced both cell length and LRD. In contrast, both low and high levels of NAA stimulated LRD in zones elongated before auxin application. Analysis of the percentage of FCs in the phloem pericycle in zones elongated in the presence or absence of NAA showed that low concentrations of NAA increased the \%PFC, indicating that $L R$ initiation is promoted at new sites; however, high concentrations of NAA elicited a considerable reduction in this variable in zones developed in the presence of auxin. As these zones are composed of short pericycle cells, we propose that short pericycle cells are incapable to participate in LR primordium initiation and that auxin modulated initiation of LRs is linked to pericycle cell length.

Keywords: lateral root development, auxin action, root elongation, pericycle, maize, Zea mays, cell growth

\section{INTRODUCTION}

Auxin is considered a key regulator of root growth, gravitropism, and lateral root (LR) formation (Muday and Haworth, 1994). Exogenous auxin treatment has typically resulted in inhibited root growth rate (Zeadan and Macleod, 1984; Hurren et al., 1988; Lloret and Pulgarín, 1992; Gaspar et al., 2003). Nevertheless, in Arabidopsis roots, it has been demonstrated that low concentrations 
of auxin can substantially stimulate primary root elongation (Evans et al., 1994). Auxin action on root development is not only a question of concentration but also of its polar translocation (Muday and DeLong, 2001). The auxin indole-3-acetic acid (IAA) is predominantly synthesized in shoots and transported basipetally from the apex to the base of the shoot (Lomax et al., 1995; Muday and DeLong, 2001; Casson and Lindsey, 2003). Once in the root, IAA moves acropetally toward the root apex through the central cylinder (Mitchell and Davies, 1975; Muday and DeLong, 2001) and basipetally from the root apex toward the elongation zone through the outer root tissues (Ohwaki and Tsurumi, 1976; Tsurumi and Ohwaki, 1978; Rashotte et al., 2000; Muday and DeLong, 2001; Ruzicka et al., 2007). Acropetal transport of IAA in the root is involved in the regulation of LR formation in Arabidopsis (Reed et al., 1998). Because basipetal IAA transport controls elongation of epidermal cells, it has been implicated in the regulation of gravitropism (Rashotte et al., 2001). As application of the auxin transport inhibitor naphthylphthalamic acid (NPA) to the tip of Arabidopsis roots inhibits both basipetal auxin transport and root elongation (Rashotte et al., 2000), it is likely that primary root elongation would also be controlled by the basipetal auxin transport mechanism. In some Arabidopsis mutants, it has been demonstrated that a reduced growth rate in primary roots is related, at least in part, to reduced elongation of individual cells (Hauser et al., 1995).

Auxin also regulates root system architecture by promoting the acquisition of founder cell (FC) identity in pericycle cells (Dubrovsky et al., 2008), and by stimulating LR development (Laskowski et al., 1995; Casimiro et al., 2003). Nevertheless, it has been reported that auxin loses its LR-promoting effect in newly formed regions of the Arabidopsis primary root growing at lower rate (Ivanchenko et al., 2010), suggesting that LR formation may be linked to cell length. Interestingly, regulation of initiation and subsequent development of LRs could be differentially controlled by basipetal (Casimiro et al., 2001) and acropetal auxin polar transport, respectively (Reed et al., 1998).

Lateral root initiation in maize begins with transversal divisions of pericycle cells associated with phloem poles, when two adjacent cells opposite the phloem undergo two almost simultaneous oblique asymmetrical divisions and later more transversal and periclinal divisions (Casero et al., 1995). In maize, periclinal divisions related to LR initiation occur $21-24 \mathrm{~mm}$ behind the tip (Casero et al., 1995). In most species, initiating LR primordia are located in the maturation zone (Lloret and Casero, 2002); consequently, the pericycle cells involved in this process are usually considered to be differenciated at the moment of LR initiation (Alarcón et al., 2016).

Several methods have been used to analyze LR development. The absolute number of LRs is not a good parameter of LR formation because it is strongly dependent on parent root length (Lloret and Pulgarín, 1992). Consequently, it evaluates not only LR formation but also main root elongation. The lateral root density (LRD) method determines the number of LRs per unit length of parent root. Currently, there is a trend to consider both emerged LRs and LR primordia, and to analyze exclusively the parent root zone that bears LRs and/or LR primordia (Lloret et al., 1988; Pulgarín et al., 1988; Dubrovsky et al., 2009). This is a better index of LR formation because it avoids distortions caused by the mother root zones where no LR initiation occurs. Another advantage of the LRD index is that it allows the comparison of LR formation in primary roots with different elongation rates. The recent implementation of the method to analyze LR formation through the determination of the "lateral root initiation index" ( $\mathrm{I}_{\mathrm{LRI}}$ ) represents a new and significant advance (Dubrovsky et al., 2009). This index describes the number of LR initiation anlages occurring along a root portion corresponding to 100 cortical cells in a file. The main advantage of using this index to describe LR initiation is that it offers a more integrative and cellular perspective, since it considers both the growth and rate of cell formation.

In this work, we show that exogenous auxin treatment of maize primary roots has a dual effect on LR formation, i.e., low doses promote the initiation of new primordia, whereas high doses inhibit this process. Therefore, the concept of auxin as a phytohormone which stimulates LR initiation should be reevaluated, as was the role of ethylene as a general root growth inhibitor (Pierik et al., 2006). To explain the contrasting effects of auxin treatment on LR initiation, we propose that auxin modulated initiation of LRs is linked to pericycle FC length.

\section{MATERIALS AND METHODS}

\section{Plant Material and Growth Conditions}

Seeds of the Zea mays L. hybrid, DK 626, were sterilized by immersion in ethanol for $5 \mathrm{~min}$. They were then washed three times and soaked in distilled water with aeration at $30^{\circ} \mathrm{C}$. After $24 \mathrm{~h}$, the seedlings, with radicles approximately $1 \mathrm{~mm}$ long, were placed vertically in holders made of Styrofoam disks, transferred into boxes, and placed in a humid environment, in the dark, at $30^{\circ} \mathrm{C}$. They were kept in these boxes for $24 \mathrm{~h}$ until the roots reached a length of $20 \pm 5 \mathrm{~mm}$. Disks with 10 selected seedlings of equal root length were placed in bottles containing $1.5 \mathrm{~L}$ aerated growth solution and grown at $30^{\circ} \mathrm{C}$ in the dark. As $\mathrm{Ca}^{2+}$ and $\mathrm{K}^{+}$are required for proper development of roots growing in hydroponic medium (Lee et al., 1983; Hasenstein and Evans, 1986; Walker et al., 1998), the growth medium consisted of a buffered solution of $1 \mathrm{mM}$ HEPES (4-(2-hydroxyethyl)-1piperazineethanesulfonic acid) supplemented with $1 \mathrm{mM} \mathrm{Ca}_{2} \mathrm{Cl}$ and $10 \mathrm{mM} \mathrm{KCl}$ at $\mathrm{pH}$ 6.0. HEPES was used as a buffering agent because it is highly soluble and chemically and enzymatically stable, in addition to having other advantages. The experimental conditions used in this study have been shown to be optimal for the growth of maize roots (Alarcón et al., 2009). After acclimation for $24 \mathrm{~h}$, when the roots were $80 \mathrm{~mm}$ long, the synthetic auxin 1naphthalene acetic acid (NAA) was added to the solution and the treatment was maintained for $48 \mathrm{~h}$. Root length was measured with a ruler (accuracy $\pm 1 \mathrm{~mm}$ ) before NAA application, and after 24 and $48 \mathrm{~h}$ of treatment. After NAA application, two 2$\mathrm{cm}$ long consecutive root zones could be distinguished, that we called zones A and B (Figure 1). The proximal A zone elongated before auxin application, indicating that cell elongation occurred in the absence of the exogenous hormone. In contrast, the distal 


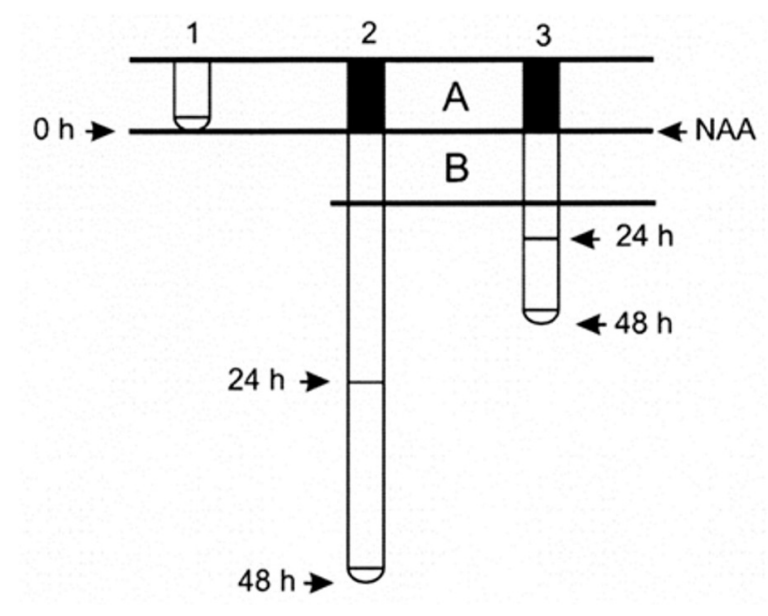

FIGURE 1 | Formation of two 2-cm long consecutive zones in the maize primary root after NAA application. At time 0 , treatment was performed by applying NAA to the growth medium (1). Zone A (filled) is elongated before auxin application, hence cell elongation occurred without auxin influence. In contrast, zone B (unfilled) elongated in the presence of auxin. Subsequently, the root grows and lateral roots develop in both zones under the influence of exogenous auxin. Note that after $48 \mathrm{~h}$, root elongation was greater in control (2) than in auxin-treated roots (3).

B zone grew in the presence of exogenous auxin. However, LR development occurred under exogenous auxin influence in both zones.

\section{Chemicals}

Concentrated solutions of NAA were prepared in $1 \mathrm{mM}$ HEPES buffer. The volumes added to the growth medium were less than $0.1 \%$ of the total volume. All the chemicals were purchased from Sigma, except $\mathrm{CaCl}_{2}$ and $\mathrm{KCl}$ (Merck).

\section{Determination of Lateral Root Density in Selected Root Zones}

To allow the development of the LR primordia until they were clearly identifiable under a dissecting microscope to facilitate quantification, roots were cultivated in growth medium for $48 \mathrm{~h}$. The primary root length was then measured and zones $\mathrm{A}$ and $B$ were selected. The root zones were fixed in FAA fixative for $48 \mathrm{~h}$. FAA is a mixture of $50 \%$ ethanol, $36 \%$ formaldehyde, and $100 \%$ acetic acid (91:6:3, v/v). The roots were subsequently transferred to $70 \%$ ethanol. LRs were quantified by observation under a dissecting microscope. The positions of the LRs were also recorded. The number of LRs that were formed during the experimental period was calculated as well as LRD in zones A and B. Both variables were determined as the number of LRs plus LR primordia per $\mathrm{cm}$.

\section{Determination of Cell Length and Parameters of LR Formation}

To measure cell length, 5-mm long central segments of zones A and $B$ were selected. These segments were embedded in paraffin and cut into $8-\mu \mathrm{m}$ serial longitudinal sections. Cell length was determined for at least five root segments for each treatment, measuring 12 cells per segment.

The calculation of the percentage of phloem pericycle cells (PPCs) that behave as FCs requires the previous determination of two variables in zones $\mathrm{A}$ and $\mathrm{B}$, namely, LRD and PPC length. To estimate this percentage, each LR primordium is assumed to originate from four phloem pericycle FCs, since LR primordium initiation in maize has been described as involving asymmetrical transverse divisions of a pair of adjacent pericycle FCs in each file (Casero et al., 1995), and that each phloem pole in maize is surrounded by two phloem pericycle cell files. The new index for LR formation that we propose is based on the percentage of PPCs (\%PPC) that behave as FCs. The percentage of PPC that become FCs was estimated by dividing the total number of FCs that gave rise to the LRs in a specific zone (equal to the number of LRs multiplied by four cells) by the total number of PPCs present within the same zone and by multiplying this ratio by 100 . The results of \%PPC are presented as the mean $\pm \mathrm{SD}$ of at least five root segments per treatment.

Another index of LR formation ( $\mathrm{I}_{\mathrm{LRI}}$ ) was calculated as established by Dubrovsky et al. (2009) for Arabidopsis roots. This index was defined to analyze the number of LRs and/or LRPs that developed in a primary root segment containing 100 cortical cells. This index was also calculated in at least five root segments per zone, and per treatment.

The relative rate of PPC cell production could be linked to LR formation. This rate of cell production (RCP) (Ivanov and Dubrovsky, 1997) can be calculated for a specific time by dividing the elongation velocity of the primary root by the average cell length of the cell type of interest. We calculated the RCP as the number of PPCs produced per meristem file per unit of time. At least five root segments were used per experimental group.

\section{Measurements and Statistical Analysis}

The values obtained for root elongation and LRD are represented as the mean $\pm \mathrm{SD}$ of 10 roots. The other variables had a sample size of at least five root segments per experimental group. Each experiment was repeated at least twice. Comparison of multiple means was performed using one-way ANOVA and Tukey's test (SPSS 13.0). Differences of means were considered significant at $P<0.05$.

\section{RESULTS}

\section{Exogenous 1-Naphthalene Acid (NAA) Application Increases LRD}

The LR distribution pattern along the primary root of maize is shown in Figure 2. The number of LRs plus LR primordia per $\mathrm{cm}$ was determined in 2-cm long control and $0.01 \mu \mathrm{M}$ NAAtreated root segments. The distribution of the LRs in control roots showed a characteristic pattern with several different zones. In the basal-most parent root segment, the density was relatively low $(15-17 \mathrm{LRs} / \mathrm{cm})$. In the segment between 2 and $4 \mathrm{~cm}$ from the base, the LRD then increased until the zone 


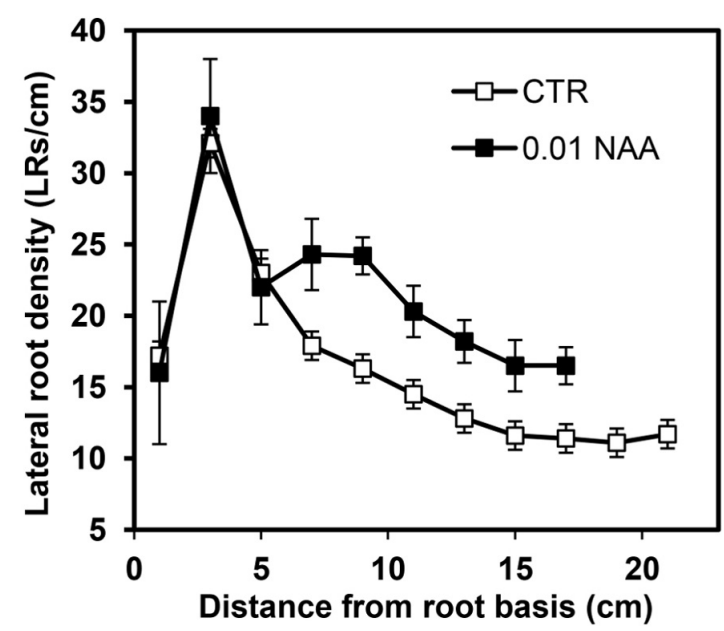

FIGURE 2 | Effect of $0.01 \mu \mathrm{M}$ NAA treatment on lateral root density (LRD) in the maize primary root. LRD was measured in 2-cm-long root segments from the base to the root tip. Auxin was applied when the roots were $8 \mathrm{~cm}$ long and LR formation was followed during a subsequent $48 \mathrm{~h}$ period. Note the inhibitory effect of NAA on root elongation and the stimulating effect on LRD in the youngest root zones analyzed. Values represent mean $\pm \operatorname{SD}(n=10)$.

of highest density (30-35 LRs/cm), and then decreased sharply to $15 \mathrm{LRs} / \mathrm{cm}$ in the segment located $6-8 \mathrm{~cm}$ from the root base. From this point toward the apex, the LRD declined slowly and then stabilized at a value close to $12 \mathrm{LRs} / \mathrm{cm}$. LR primordia were not detected in the zone adjacent to the root apex.

The application of $0.01 \mu \mathrm{M}$ NAA stimulated the formation of LRs in the primary root of maize. This stimulation was observed as a wide extension of the parent root, mainly affecting the more distal root segments (Figure 2); in the youngest root segments grown after NAA treatment, significant LRD stimulation (treated: $24.3 \pm 3.0$ LRs/cm vs. control: $15.9 \pm 2.5 \mathrm{LRs} / \mathrm{cm}$ ) was observed. Promotion of LR formation also occurred in new segments formed after beginning of treatment. In contrast, more proximal root zones were apparently insensitive to auxin treatment (Figure 2).
In addition, application of $0.01 \mu \mathrm{M}$ NAA inhibited primary root elongation by $30 \%$ and reduced the number of segments along the root where LRs normally form. Consequently, a relationship between the parent root growth and LR formation was analyzed in more details.

\section{Relationship Between Primary Root Elongation and Lateral Root Formation}

Maize primary root elongation was inhibited by NAA treatment in a concentration-dependent manner, with a consequent reduction of the area where LRs can develop (Table 1). A low NAA concentration $(0.01 \mu \mathrm{M})$ marginally inhibited primary root elongation, but increased the total number of LRs after $48 \mathrm{~h}$ of treatment (Figures 3A,B). However, higher NAA concentrations elicited a large reduction in the absolute number of LRs (Figure 3A), as well as a strong concomitant reduction in primary root elongation. Therefore, the inhibition of LR formation could be due, at least in part, to the reduction in primary root elongation. Concentrations of NAA in the $0.05-0.1 \mu \mathrm{M}$ range resulted in stronger inhibition of root elongation (up to 75\%), and $0.5 \mu \mathrm{M}$ NAA completely inhibited primary root elongation (data not shown). When primary root elongation is inhibited, LR primordia have limited physical space to develop, and LRD (number of LRs and/or LR primordia per unit length) may therefore be a better index to evaluate LR formation than the absolute number of LRs. Figure 3C shows that 0.01 and $0.05 \mu \mathrm{M}$ NAA significantly increased the average LRD. However, the stimulatory effect was lost with application of higher doses of NAA. This suggests that high concentrations of auxin, which resulted in strongly reduced primary root elongation, inhibit LR formation.

Moreover, strong inhibition of primary root elongation could result in segments located in the same position in both control and treated roots not forming at the same time (Figure 1). As segments at the same position would not be homologous, comparison of LRD between control and treated roots becomes difficult, and even meaningless in extreme cases. Therefore, it is appropriate, as far as possible, to compare root segments of the same age and similar relative location along the primary root (homologous segments).

TABLE 1 | Concentration-dependent effects of NAA on cell length and root elongation.

\begin{tabular}{|c|c|c|c|c|}
\hline Zone & Groups & Root elongation (mm/48 h) & ECL $(\mu \mathrm{m})$ & CCL $(\mu \mathrm{m})$ \\
\hline$A$ & 0.00 NAA & $129.3 \pm 9.1(100) a$ & $152.8 \pm 6.3$ (100)a & $191.9 \pm 14.1$ (100)a,b \\
\hline A & $0.01 \mathrm{NAA}$ & - & $144.4 \pm 17.5(95) \mathrm{a}$ & $182.7 \pm 9.5(95) a, b$ \\
\hline A & $0.05 \mathrm{NAA}$ & - & $150.6 \pm 18.9(99) a$ & $168.6 \pm 11.0(88) b$ \\
\hline A & $0.10 \mathrm{NAA}$ & - & $151.6 \pm 21.3(99) a$ & $204.4 \pm 15.5$ (107)a \\
\hline$B$ & $0.00 \mathrm{NAA}$ & $128.4 \pm 17.3(100) \mathrm{a}$ & $154.8 \pm 20.5(100) a$ & $195.6 \pm 13.1(100) a$ \\
\hline$B$ & $0.01 \mathrm{NAA}$ & $97.4 \pm 17.0(76) \mathrm{b}$ & $121.2 \pm 10.5(78) b$ & $167.0 \pm 16.0(85) b$ \\
\hline$B$ & $0.05 \mathrm{NAA}$ & $50.7 \pm 9.3(39) c$ & $60.6 \pm 11.4(39) c$ & $91.8 \pm 10.5(47) c$ \\
\hline$B$ & $0.10 \mathrm{NAA}$ & $31.8 \pm 3.5(25) d$ & $48.5 \pm 2.5(31) c$ & $65.2 \pm 11.3(33) d$ \\
\hline
\end{tabular}

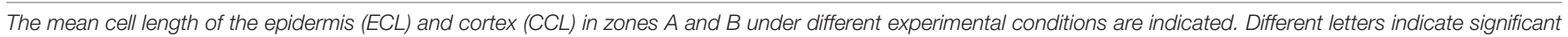

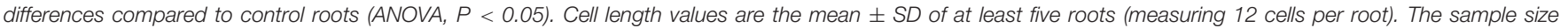

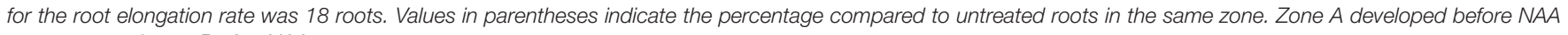
treatment, and zone $B$ after NAA treatment. 


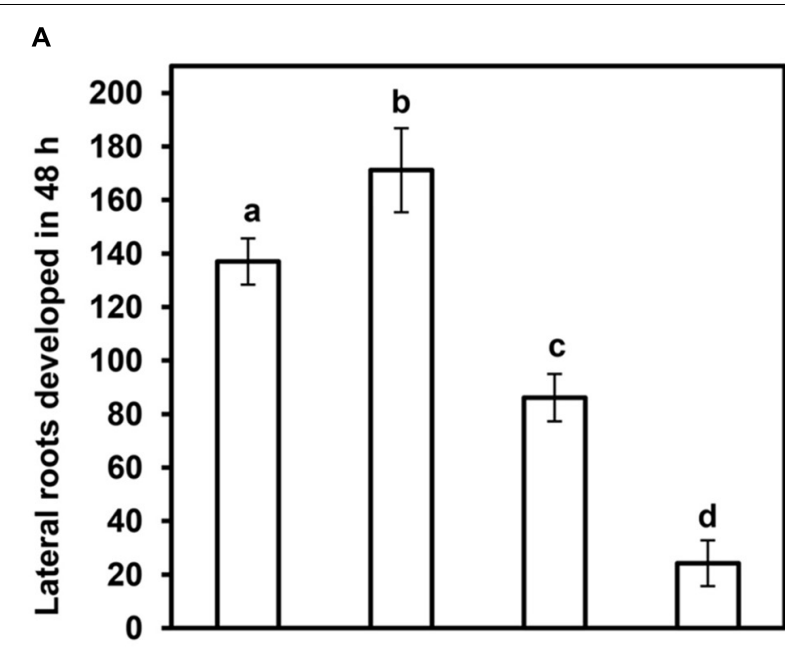

B

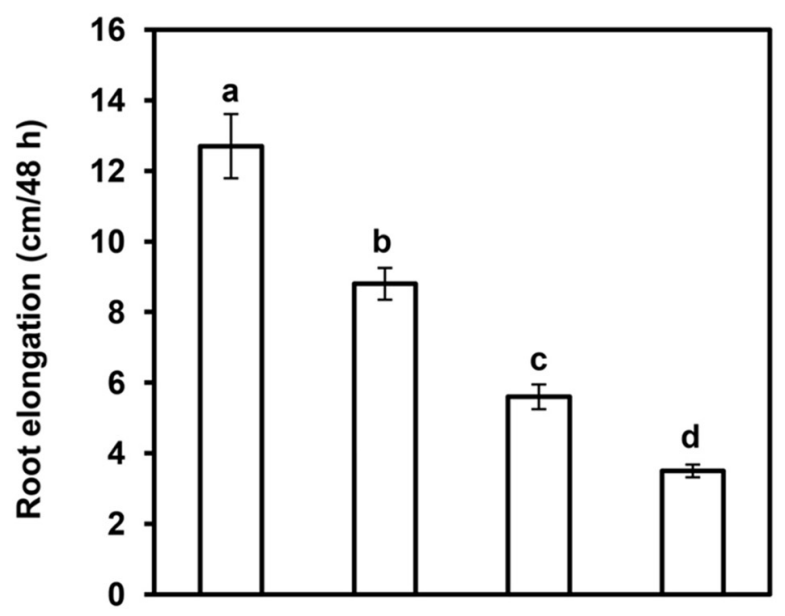

C

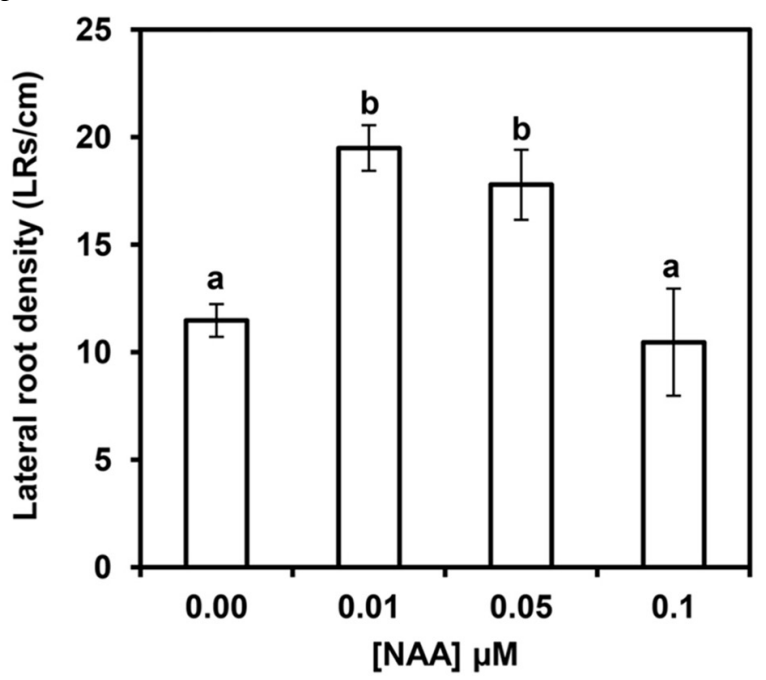

FIGURE 3 | Effects of several NAA concentrations on lateral root (LR) formation and primary root elongation within $48 \mathrm{~h}$ after NAA application. Number of LRs plus LR primordia (A), primary root elongation (B), and average LRD $(\mathbf{C})$ in the formed segments of primary maize roots. Values are mean $\pm \operatorname{SD}(n=10)$. Different letters indicate significant differences at $P<0.05$ (ANOVA and Tukey's test).

\section{Root Zones Formed Before and After NAA Treatment}

At the beginning of NAA treatment, there were two homologous zones in control and treated roots which were formed. We called these zone A and zone B (Figure 1), and they exhibit several clear differentiating features. The main difference between the two zones was that the A zone elongated in the absence of exogenous auxin, but LR development occurred in the presence of NAA; as meanwhile, the B zone elongated and initiated LR primordia in the presence of auxin. Corresponding zone in untreated roots was defined as a root portion formed during the same time. Additionally, these two zones showed different thickness, LRD, and stages of LR primordium development (Figure 4).

Auxin application elicits a progressive increase in the thickness of zone A (Figure 4), without apparently affecting LR primordium initiation or development (Figure 4). In contrast, LR development appeared to be altered in the B zone (Figure 4). The existence of these two segments that developed in a short period, but under different physiological conditions, allows the separation of the effects of auxin on root elongation and LR formation.

\section{NAA Application Elicits Different Effects on LRD in Zones A and B}

The obtained $L R D$ values for untreated primary roots for zones $\mathrm{A}$ and $\mathrm{B}$ were $18.8 \pm 2.9$ and $17.6 \pm 1.8$, respectively (Table 2). These results did not differ significantly $(P>0.05$, ANOVA and Tukey's test for unplanned comparisons). The application of NAA at $0.01,0.05$, and $0.1 \mu \mathrm{M}$ concentrations significantly increased LRD in zone A. This variable increased from $18.8 \pm 2.9$ in untreated roots to an average of approximately 25 LRs per $\mathrm{cm}$ in NAA-treated roots. No significant differences in LRD were found between different NAA concentrations, showing that the stimulatory effect seen in zone A was independent of NAA concentration (Table 2). In contrast, the effect of NAA on LR development in zone B was concentration-dependent. As in zone A, application of $0.01 \mu \mathrm{M}$ NAA resulted in a significant increase in LRD. However, with $0.05 \mu \mathrm{M}$ NAA, LRD stimulation was lost, and was reduced to values lower than observed for control roots with the highest NAA doses (Table 2).

\section{Reduction of Epidermal and Cortical Cell Length by NAA Treatments}

We measured epidermal and cortical cell length in zones A and $\mathrm{B}$ of both control and NAA-treated roots. The majority of cells in zone A had finished elongating at the onset of auxin treatment. Therefore, we expected that NAA application would not affect cell length in zone A. Indeed, our results showed that the length of epidermal cells was not reduced in this zone with any NAA dose used (Table 1); moreover, cortical cell length in zone A also showed a tendency to maintain cell length. In relation to cortical cell length, the tendency was also to maintain similar values in both treated and control roots. The minimum length was recorded in roots treated with $0.05 \mu \mathrm{m}$ NAA ( $12 \%$ reduced vs. control roots). However, this reduction in cell length was not statistically significant (Table 1). 


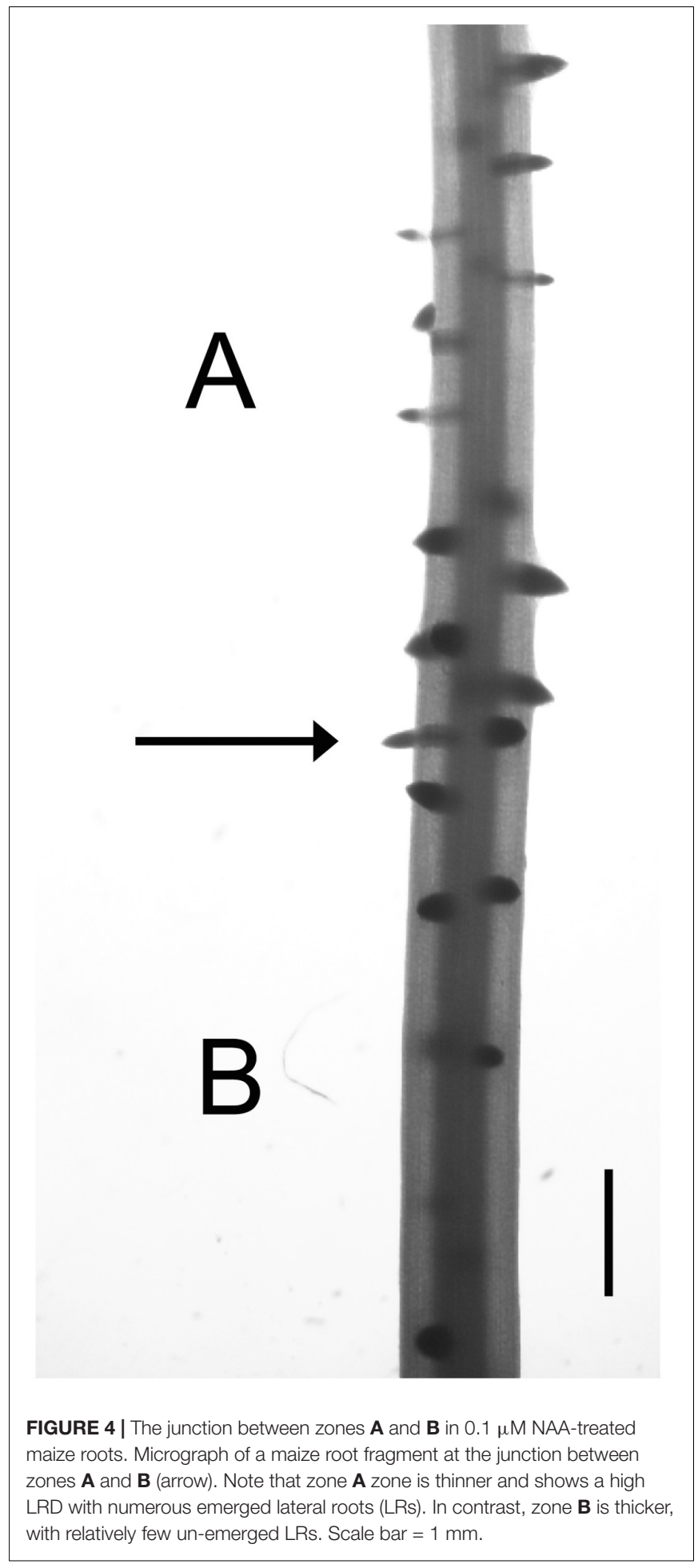

In zone $\mathrm{B}$, inhibition of root elongation by NAA was always accompanied by a reduction in the length of epidermal and cortical cells (Table 1). This reduction was progressive and always statistically significant, except for the epidermal cells of the group treated with $0.1 \mu \mathrm{M}$ NAA, where cell length was $48.1 \mu \mathrm{m}$, likely near the lower limit for non-elongated cells (Table 1).

\section{Reduction of Pericycle Cell Length by NAA Results in Decreased LRD}

To study a possible relationship between pericycle cell length and LR formation, both parameters were analyzed comparatively in roots treated with several concentrations of NAA (Table 2). The mean PPC length in zone A of control roots was $264.3 \pm 22.8 \mu \mathrm{m}$. In a given root segment, the number of PPCs in a cell file can be calculated by dividing the total length of the segment by the mean length of PPCs. In our sample, the mean number of phloem poles was 15 and the number of PPC cell files at each phloem pole was calculated as two. Consequently, the total number of PPCs in a specific root segment can be estimated by multiplying by 30 ( 2 PPC cell files per pole and 15 phloem poles) the average number of cells in a pericycle cell file along the entire length of the segment.

As we consider that each LR primordium originated from four FCs per phloem pole, and LRD was $18.8 \pm 2.9$ in zone A of control roots, the percentage of FCs out of total number of PPC is equal to $6.5 \pm 0.5$ (Table 2). Application of $0.01,0.05$, or $0.1 \mu \mathrm{M}$ NAA did not significantly affect the length of pericycle cells in zone A, but the LRD was significantly increased (Figure 3C). Hence, the percentage of FCs increased from 6.5 to 10.4, 9.6, and 9.1, respectively, after NAA treatment (Table 2). A similar increase in LR formation was observed when the lateral root initiation index (IRI) was calculated according to Dubrovsky et al. (2009).

In zone B of untreated roots, the values for PPC length, LRD, percentage of FCs, and $\mathrm{I}_{\text {LRI }}(265.8 \mu \mathrm{m}, 17.6 \mathrm{LRs} / \mathrm{cm}, 6.1 \%$, and 33.8 , respectively) were similar to those found in zone $\mathrm{A}$ (Table 2). Application of $0.01 \mu \mathrm{M}$ NAA promoted a significant increase in LRD (24.9 LRs/cm) in zone B, which was accompanied by a parallel increase in the percentage of FCs $(8.2 \%)$ and $\mathrm{I}_{\text {LRI }}(41.6 \%)$ compared with control roots (Table 2). However, treatments with higher concentrations of NAA significantly reduced the mean PPC length, LRD, percentage of FCs, and ILRI (Table 2). Taken together, these data clearly show that the inhibition of PPC elongation by high NAA concentrations resulted in a reduced rate of LR formation.

We also determined the RCP values to establish whether there was a reduction in pericycle cell production in roots subjected to treatments with high concentrations of auxin. It was possible that this reduction could be linked to a decrease in the rate of LR primordium production. In control roots, this variable showed values of $7.8 \pm 1.3$ and $9.6 \pm 0.4$ cells per row per hour for zones $\mathrm{A}$ and $\mathrm{B}$, respectively, when they formed (Table 2 ). This variable decreased in treated roots until reaching a minimum value of $6.1 \pm 09$ PPCs per cell file per hour in zone B. Consequently, there was a reduction of approximately $35 \%$ in the RCP. However, the apical meristem of the root never ceased producing new cells.

\section{DISCUSSION}

\section{Competence Period for LR Initiation}

Studies in different species have tended to confirm that pericycle cells respond only to factors that trigger LR 
TABLE 2 | Lateral root formation in maize roots under different exogenous auxin treatments.

\begin{tabular}{|c|c|c|c|c|c|c|}
\hline Zone & Groups & PPCL & LRD & $\% F C$ & ILRI & RCP \\
\hline$A$ & $0.00 \mathrm{NAA}$ & $264.3 \pm 22.8 a$ & $18.8 \pm 2.9 a$ & $6.5 \pm 0.5 a$ & $36.0 \pm 5.0 a$ & $7.8 \pm 1.3 \mathrm{a}$ \\
\hline A & $0.01 \mathrm{NAA}$ & $279.0 \pm 18.1 \mathrm{a}$ & $25.5 \pm 2.8 b$ & $10.4 \pm 1.2 b$ & $50.9 \pm 5.2 b$ & $6.9 \pm 1.6 a$ \\
\hline A & $0.05 \mathrm{NAA}$ & $268.8 \pm 12.5 a$ & $25.9 \pm 2.5 b$ & $9.6 \pm 1.0 b$ & $45.2 \pm 4.4 b$ & $7.7 \pm 0.5 a$ \\
\hline A & $0.10 \mathrm{NAA}$ & $277.2 \pm 32.4 a$ & $24.8 \pm 2.6 b$ & $9.1 \pm 1.6 b$ & $50.2 \pm 7.3 b$ & $7.8 \pm 1.4 a$ \\
\hline$B$ & $0.00 \mathrm{NAA}$ & $265.8 \pm 12.8 \mathrm{a}$ & $17.6 \pm 1.8 \mathrm{a}$ & $6.1 \pm 0.9 a$ & $33.9 \pm 4.7 a$ & $9.6 \pm 0.4 a$ \\
\hline$B$ & $0.01 \mathrm{NAA}$ & $248.1 \pm 40.7 a$ & $24.9 \pm 1.4 b$ & $8.2 \pm 1.2 b$ & $41.6 \pm 4.8 b$ & $7.2 \pm 1.7 b$ \\
\hline$B$ & 0.05 NAA & $139.4 \pm 23.2 b$ & $21.5 \pm 3.3 c$ & $4.3 \pm 0.6 c$ & $21.4 \pm 1.8 c$ & $6.2 \pm 0.7 b$ \\
\hline$B$ & $0.10 \mathrm{NAA}$ & $110.1 \pm 17.4 b$ & $10.6 \pm 2.6 d$ & $1.7 \pm 0.3 d$ & $7.5 \pm 1.4 d$ & $6.1 \pm 0.9 b$ \\
\hline
\end{tabular}

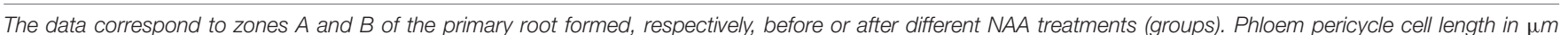

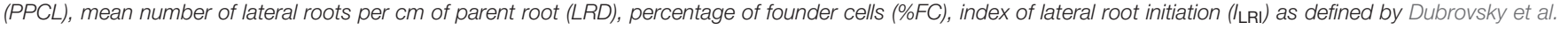

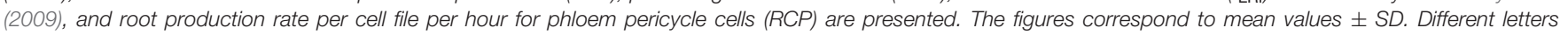

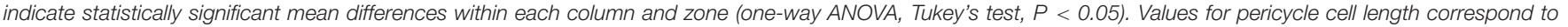
five roots, measuring at least 15 cells per root. The $L R D$ was calculated from 10 roots. The percentage of FCs was calculated based on known values of $L R D$ and PPCL, and assuming that the maize root has 15 poles of phloem, each of them with two columns of pericycle cells, and that each LR is initiated from four PPCLs.

initiation during a short period of time, called the competence period or developmental window (Abadía-Fenoll et al., 1986; Dubrovsky et al., 2006). The existence of a competence period results in LR initiation following an essentially acropetal sequence, with new LR primordia initiating distally to those formed previously (Lloret and Casero, 2002). According to Dubrovsky and Rost (2012), at least two events must occur in Arabidopsis thaliana roots before the first cell divisions of LR primordium organogenesis occur, namely, priming and specification of pericycle FCs. Priming can be considered as cell commitment to LR formation. In most higher plant species, this phenomenon occurs in the transition zone between the root apical meristem and the elongation zone (Dubrovsky and Rost, 2012). Specification consists of pericycle FCs acquiring a developmental fate different from other pericycle cells, and participating in LR primordium initiation (Dubrovsky and Rost, 2012). Local accumulation of free auxin has been shown to be a prerequisite for FC specification (Dubrovsky et al., 2008). Priming and specification can occur within a time interval shorter than a cell cycle (Dubrovsky and Rost, 2012). Consequently, these two processes should be concluded when pericycle cells eventually reach the end of the elongation zone, explaining the narrow developmental window for LR initiation.

Our results presented in Figure 2 support the hypothesis of the existence of a short competence period for LR initiation. Indeed, only the youngest root fragments increase their LRD in response to treatment with $0.01 \mu \mathrm{m}$ NAA. Stimulation of LR formation by auxin in newly formed root zones is expected as this hormone is considered the main regulator of LR formation (Lloret and Pulgarín, 1992; Hobbie, 1998; Lloret and Casero, 2002), and numerous young pericycle cells capable of becoming FCs exist in this region (Dubrovsky et al., 2006). In the preformed regions close to the root apical meristem, we also found that NAA treatment stimulated LR formation. This suggests that pericycle cells that are primed, but not specified, will eventually develop LRs as a result of the treatment. In this case and under normal conditions, the possible regions for LR formation would be more abundant than regions where LR primordia will eventually develop.

\section{Pericycle Cell Length and Auxin Response During LR Formation}

It is well-known that exogenous auxin treatment normally promotes LR formation in several plant species (Zeadan and Macleod, 1984; Hurren et al., 1988; Lloret and Pulgarín, 1992; Zhang and Hasenstein, 1999; Nieuwland et al., 2009). Overall, the high auxin concentrations used in these experiments also inhibited primary root elongation, posing the question as to whether both effects of auxin on root system development are related. Recent evidence suggests complex effects of auxin on LR initiation in $A$. thaliana roots showing reduced cell elongation (Ivanchenko et al., 2010). The above mentioned study demonstrated that when the primary root elongation rate is reduced, the promotion of LR formation by auxin diminishes with increasing concentrations of this phytohormone. Our results in $Z$. mays agree entirely with those obtained in A. thaliana roots. The suggested connection between inhibition of primary root elongation and reduced LR formation would be mediated by a decrease in the sensitivity of pericycle cells to auxin under conditions of reduced growth (Ivanchenko et al., 2010).

We propose an alternative hypothesis to explain the same phenomenon in maize roots. The loss of the ability of auxin to stimulate LR formation when applied at high concentration may be due to the substantial reduction in cell length occurring in the pericycle of maize under conditions of reduced growth. Notably, in the study by Ivanchenko et al. (2010), a maximum inhibition of approximately $8 \%$ in cortical cell length was achieved, whereas in our experiments we observed a reduction in length of nearly $60 \%$ (Table 2). Our hypothesis does not exclude that other factors apart from cell length may be linked to the mechanism that controls LR formation under conditions of reduced growth of the primary root. However, variations in the length of pericycle FCs fully and reasonably justify the behavior of LR initiation observed in our experiments. 
Our analysis of LRD in zones A and B of the maize root is especially important. Zone A corresponded to the apical-most $2 \mathrm{~cm}$ of primary root length when NAA treatment began and, consequently, had a pericycle too young to show advanced stages of LR development. Zone B was generated by the apical meristem during NAA treatment and new LRs were formed during the same time and under the same treatment. Nevertheless, the elongation process was different between the two root zones. In our experiment, zone A cells located proximally to the elongation zone grew without the influence of auxin. In contrast, in the $\mathrm{B}$ zone, the root elongation process occurred in the presence of auxin. Consequently, this experimental system can discriminate whether an effect on LR formation is independent or dependent of root elongation.

In our experiments, roots treated with 0.01 and $0.05 \mu \mathrm{M}$ NAA showed increased LRD, in both the A and B zones. Nevertheless, strong NAA doses $(0.1 \mu \mathrm{M})$ increased LRD in zone $A$, but not in zone $\mathrm{B}$. This indicates that the promoting effect of auxin on LR formation is lost in the latter zone with $0.1 \mu \mathrm{M}$ auxin treatment. The situation in zone B contrasted with the stimulation of LRD in zone A after the same auxin treatment. The most likely explanation for this phenomenon is that the high auxin concentration used in this experiment interacts with another factor to elicit a differential response in zones A and B.

Maize LRs originate from pericycle FCs located opposite the phloem poles of the parent root (Casero et al., 1995). The initiation of LRs depends on a controlled sequence of cell divisions, some of which are asymmetrical (Casero et al., 1995). Studies in diverse organisms, from bacteria to vertebrates, indicate that cell cycle commitment to the G1 to $S$ phase transition requires that cells grow to a critical size, which is an active mechanism to ensure cell size homeostasis (Dungrawala et al., 2012). Recent evidence in plants also suggests that cell size is one of the variables controlling cell cycle progression (Rioboo et al., 2009; Bush et al., 2015; Löfke et al., 2015; Jones et al., 2017). Cells must have a mechanism for coordinating their rates of cell growth and division. In budding yeast, growth to a "critical cell size" must be achieved before cells pass the check point known as START and transition from the G1 to the S phase (Dungrawala et al., 2012). The START point is equivalent to the restriction point in mammalian cells (Dungrawala et al., 2012). Therefore, it is possible that most pericycle cells in zone B in our study, had lost their ability to proliferate and launch LR primordium initiation as a result of their extremely short length after treatment with auxin $0.1 \mu \mathrm{M}$ NAA. Conversely, it has been demonstrated that when the Arabidopsis root is bent there is a strict correlation between cell size, auxin transport, and stimulation of LR formation in the convex side of the curvature (Laskowski et al., 2008). In this system, a maximal level of auxin is established on the convex side of the curvature where LR primordia are initiated, whereas on the concave side of the curvature, where short pericycle cells are located, LR primordia do not develop.

As with other developmental processes, LR initiation requires that a series of asymmetrical cell divisions take place (Casero et al., 1995). Alterations in cell expansion could affect not only the ability of pericycle cells to divide, but also their ability to divide asymmetrically. During the segmentation of new colonies of the green alga Volvox, gonidial cells are produced after asymmetrical cell divisions. It has been demonstrated that the large size of the gonidial cells is the primary reason for differences in cell fate, morphologic characteristics, and cell division behavior compared to somatic cells (Kirk et al., 1993). In plants, the polarized expansion of the wall may be a mechanism that promotes asymmetries in cell division (Menke and Scheres, 2009). In addition, it has been proposed an inhibition of asymmetrical divisions in short pericycle cells during LR initiation (De Smet et al., 2008).

Moreover, it was recently shown that overexpression of the small peptide GLV6 disrupted the first asymmetric divisions required for the formation of a viable LR primordium, resulting in a reduced number of emerged LRs (Fernandez et al., 2015). It is well known that GLV peptides are also implicated in the regulation of cell elongation (Ghorbani et al., 2016). Consequently, pericycle cell elongation and LR initiation are likely to be interrelated processes.

The reduction in the density of LR primordia observed when NAA was applied at high concentrations could be related to a reduction in the rate of production of cells in the root apical meristem, or a consequence of the shortening of pericycle cell length. Indeed, cell became shorter even though NAA did not completely inhibit root elongation. Importantly, the RCP value for the PPC responsible for the initiation of LR primordia was maintained at a level of approximately six cells per cell file per hour (Table 2), apparently sufficient to promote a high density of LR primordia. However, the results presented here suggest that the specification process for LR initiation in PPCs is highly compromised when cell elongation is strongly reduced.

Therefore, pericycle cell length could play an important role in regulating the formation of LRs. For maize roots at least, LR initiation can no longer be interpreted only from an organismal perspective. In pericycle cells, in addition to regulatory effects that operate at the level of the whole plant, cell length appears to be a possible modulator in the control of LR initiation.

\section{Quantification of LR Formation}

The quantification of LR formation is an important but somewhat complex topic (Dubrovsky et al., 2009). One difficulty to consider is that both already emerged LRs and endogenous LR primordia are not visible unless you clear the root or obtain histological sections. Another difficulty is that comparisons must frequently be established between roots of different ages and lengths that have been growing at very different growth rates. Hence, our results should be normalized to enable meaningful comparisons between root zones with homologous development (Figure 1).

To compensate for the influence of the primary root length on LR formation, two useful strategies have been developed to date. The first is to divide the number of LRs (independently of whether they are LR initiation events or already emerged roots) by the length of the region of the primary root containing both LRs and LR primordia (Lloret et al., 1988; Lloret and Pulgarín, 1992). A regularly used alternative option for this type of calculation has been to divide the length of the primary root into segments of fixed length and recount the number of LRs present in each segment (Hummon, 1962; Lloret et al., 1988; 
MacLeod, 1990; Varney et al., 1991; Lloret and Pulgarín, 1992). The second strategy consists of relating LR formation indices to the intervening cells between successive initiation events (Lloret et al., 1985; Dubrovsky et al., 2009). This protocol is useful because it adjusts the results for the differences in primary root growth rate. Both methods have advantages and disadvantages, but indices based on the latter type are the most appropriate from the point of view of developmental biology because they reveal whether the FCs were produced by the root apex at a regular rhythm.

However, not all FCs formation result in LR development, and then the longitudinal spacing pattern of LRs becomes more difficult to evaluate (Charlton, 1983; Barlow and Adam, 1988; Lloret and Casero, 2002). Recently, this issue was revisited in the model plant $A$. thaliana (Dubrovsky et al., 2006). In the same species, an index based on cortical cell length, called the lateral root initiation index $\left(\mathrm{I}_{\mathrm{LRI}}\right)$, has been applied to study $\mathrm{LR}$ distribution patterns (Dubrovsky et al., 2009). Here, we present a new method to evaluate LR formation that is relatively simple but highly effective in estimating LR formation, namely, the percentage of FCs.

The ILRI proposed by Dubrovsky et al. (2009) defines root segments as a function of the length of fully elongated cortical cells. Nevertheless, LR initiation starts in pericycle FCs, and it may be more appropriate to relate the index to pericycle cells instead of cortical cells. Therefore, we directly calculated the percentage of FCs. Despite the differences, these indices produced similar estimations of LR formation under different experimental conditions (see Table 2). For example, the increase in the percentage of pericycle FCs compared to the control was $48 \%$ in roots treated with $0.05 \mu \mathrm{M}$ NAA. This change is consistent with the reduced length of epidermal or cortical

\section{REFERENCES}

Abadía-Fenoll, F., Casero, P. J., Lloret, P. G., and Vidal, M. R. (1986). Development of lateral primordia in decapitated adventitious roots of Allium cepa. Ann. Bot. 58, 103-107. doi: 10.1093/oxfordjournals.aob.a087178

Alarcón, M. V., Lloret, P. G., Iglesias, D. J., Talón, M., and Salguero, J. (2009). Response of maize seedling roots to changing ethylene concentrations. Russ. J. Plant Physiol. 56, 488-494. doi: 10.1134/S1021443709040074

Alarcón, M. V., Lloret, P. G., Martín-Partido, G., and Salguero, J. (2016). The initiation of lateral roots in the primary roots of maize (Zea mays L.) implies a reactivation of cell proliferation in a group of founder pericycle cells. J. Plant Physiol. 192, 105-110. doi: 10.1016/j.jplph.2016.02.005

Barlow, P. W., and Adam, J. S. (1988). The position and growth of lateral roots on cultured root axes of tomato, Lycopersicon esculentum (Solanaceae). Plant Syst. Evol. 158, 141-154. doi: 10.1007/BF00936340

Bush, M. S., Crowe, N., Zheng, T., and Doonan, J. H. (2015). The RNA helicase, eIF4A-1, is required for ovule development and cell size homeostasis in Arabidopsis. Plant J. 84, 989-1004. doi: 10.1111/tpj.13062

Casero, P. J., Casimiro, I., and Lloret, P. G. (1995). Lateral root initiation by asymmetrical transverse divisions of pericycle cells in four plant species: Raphanus sativus, Helianthus annuus, Zea mays, and Daucus carota. Protoplasma 188, 49-58. doi: 10.1007/BF01276795

Casimiro, I., Beeckman, T., Graham, N., Bhalerao, R., Zhang, H. M., Casero, P., et al. (2003). Dissecting Arabidopsis lateral root development. Trends Plant Sci. 8, 165-171. doi: 10.1016/S1360-1385(03)00051-7

Casimiro, I., Marchant, A., Bhalerao, R. P., Beeckmann, T., Dhooge, S., Swarup, R., et al. (2001). Auxin transport promotes Arabidopsis lateral root initiation. Plant Cell 13, 843-852. doi: 10.1105/tpc.13.4.843 cells occurring under the same treatment (39 and 47\%, see Table 1). In contrast, an increase of approximately $30 \%$ is observed if the index is calculated using cortical cell length ( ILRI $_{\text {L }}$.

In summary, a new index based on the percentage of pericycle cells that produce LR primordia is presented in this report. This index provides a more accurate tool for the estimation of LR formation, as the measurements are made on pericycle FCs which initiate LR formation, and are the most directly implicated in this process. In addition, we compared this new index with a previous index based on cortical cell length and obtained similar results. The results of our study also showed that auxin modulated initiation of LRs is closely linked to pericycle cell length.

\section{AUTHOR CONTRIBUTIONS}

MA, JS, and PL conceived the study, contributed to methodology, wrote the original draft, and acquired the funding.

\section{FUNDING}

This work was supported by grants to research groups GR15158, GR18114 from Junta de Extremadura, and by FEDER funds, and CCESAGROS project.

\section{ACKNOWLEDGMENTS}

We thank Alberto Lloret-Salamanca for reviewing our text in English.

Casson, S. A., and Lindsey, K. (2003). Genes and signalling in root development. New Phytol. 158, 11-38. doi: 10.1046/j.1469-8137.2003.t01-1-00705.x

Charlton, W. A. (1983). "Patterns and control of lateral root initiation," in Growth Regulators in Root Development, eds M. B. Jackson and A. D. Stead (London: Monograph 10, British Plant Regulator Group), 1-14.

De Smet, I., Vassileva, V., De Rybel, B., Levesque, M. P., Grunewald, W., Van Damme, D., et al. (2008). Receptor-like kinase ACR4 restricts formative cell divisions in the Arabidopsis root. Science 322, 594-597. doi: 10.1126/science. 1160158

Dubrovsky, J. G., Gambetta, G. A., Hernández-Barrera, A., Shishkova, S., and González, I. (2006). Lateral root initiation in Arabidopsis: developmental window, spatial patterning, density and predictability. Ann. Bot. 97, 903-915. doi: $10.1093 / \mathrm{aob} / \mathrm{mcj} 604$

Dubrovsky, J. G., and Rost, T. L. (2012). "Pericycle," in eLS, 2nd Edn, (Chichester: John Whiley and Sons), 1-10. doi: 10.1002/9780470015902.a000 2085.pub2

Dubrovsky, J. G., Sauer, M., Napsucialy-Mendivil, S., Ivanchenko, M. G., Friml, J., Shishkova, S., et al. (2008). Auxin acts as a local morphogenetic trigger to specify lateral root founder cells. Proc. Natl. Acad. Sci. U.S.A. 105, 8790-8794. doi: 10.1073/pnas.0712307105

Dubrovsky, J. G., Soukup, A., Napsucialy-Mendivil, S., Jeknic, Z., and Ivanchenko, M. G. (2009). The lateral root initiation index: an integrative measure of primordium formation. Ann. Bot. 103, 807-817. doi: 10.1093/aob/mcn267

Dungrawala, H., Hua, H., Wright, J., Abraham, L., Kasemsri, T., Mcdowell, A., et al. (2012). Identification of new cell size control genes in S. cerevisiae. Cell Div. 7:24. doi: 10.1186/1747-1028-7-24

Evans, M. L., Ishikawa, H., and Estelle, M. A. (1994). Responses of Arabidopsis roots to auxin studied with high temporal resolution: comparison of wild 
type and auxin-response mutants. Planta 194, 215-222. doi: 10.1007/BF011 01680

Fernandez, A., Drozdzecki, A., Hoogewijs, K., Vassileva, V., Madder, A., Beeckman, T., et al. (2015). The GLV6/RGF8/CLEL2 peptide regulates early pericycle divisions during lateral root initiation. J. Exp. Bot. 66, 5245-5256. doi: $10.1093 /$ jxb/erv329

Gaspar, T. H., Kevers, C., Faivre-Rampant, O., Crèvecour, M., Penel, C. L., Greppin, H., et al. (2003). Changing concepts in plant hormone action. Vitro Cell. Dev. Biol. Plant 39, 85-106. doi: 10.1079/IVP2002393

Ghorbani, S., Hoogewijs, K., Pecenkova, T., Fernandez, A., Inze, A., Eeckhout, D., et al. (2016). The SBT6.1 subtilase processes the GOLVEN1 peptide controlling cell elongation. J. Exp. Bot. 67, 4877-4887. doi: 10.1093/jxb/erw241

Hasenstein, K. H., and Evans, M. L. (1986). Calcium dependence of rapid auxin action in maize roots. Plant Physiol. 81, 439-443. doi: 10.1104/pp.81.2.439

Hauser, M. T., Morikami, A., and Benfey, P. N. (1995). Conditional root expansion mutants of Arabidopsis. Development 121, 1237-1252.

Hobbie, L. J. (1998). Auxin: molecular genetic approaches in Arabidopsis. Plant Physiol. Biochem. 36, 91-102. doi: 10.1016/S0981-9428(98)80094-6

Hummon, M. R. (1962). The effects of tritiated thymidine incorporation on secondary root production by Pisum sativum. Am. J. Bot. 49, 1038-1046. doi: 10.1002/j.1537-2197.1962.tb15044.x

Hurren, N. G., Zeadan, S. M., and Macleod, R. D. (1988). Lateral root development in attached and excised roots of Zea mays L. cultivated in the presence or absence of indol-3-yl acetic acid. Ann. Bot. 61, 573-579. doi: 10.1093/ oxfordjournals.aob.a087591

Ivanchenko, M. G., Napsucialy-Mendivil, S., and Dubrovsky, J. G. (2010). Auxininduced inhibition of lateral root initiation contributes to root system shaping in Arabidopsis thaliana. Plant J. 64, 740-752. doi: 10.1111/j.1365-313X.2010. 04365.x

Ivanov, V. B., and Dubrovsky, J. G. (1997). Estimation of the cell-cycle duration in the root apical meristem: a model of linkage between cell-cycle duration, rate of cell production, and rate of root growth. Int. J. Plant Sci. 158, 757-763. doi: $10.1086 / 297487$

Jones, A. R., Forero-Vargas, M., Withers, S. P., Smith, R. S., Traas, J., Dewitte, W., et al. (2017). Cell-size dependent progression of the cell cycle creates homeostasis and flexibility of plant cell size. Nat. Commun. 8:15060. doi: 10. 1038/ncomms 15060

Kirk, M. M., Ransik, A., Mcrae, S. E., and Kirk, D. L. (1993). The relationship between cell size and cell fate in Volvox carteri. J. Cell Biol. 123, 191-208. doi: $10.1083 /$ jcb.123.1.191

Laskowski, M., Grieneisen, V. A., Hofhuis, H., Ten Hove, C. A., Hogeweg, P., Marée, A. F. M., et al. (2008). Root system architecture from coupling cell shape to auxin transport. PLoS Biol. 6:e307. doi: 10.1371/journal.pbio.0060307

Laskowski, M. J., Williams, M. E., Nusbaum, H. C., and Sussex, I. M. (1995). Formation of lateral root meristems is a two-stage process. Development 121 , 3303-3310.

Lee, J. S., Mulkey, T. L., and Evans, M. L. (1983). Gravity-induced polar transport of calcium across root tips of maize. Plant Physiol. 73, 874-876. doi: 10.1104/ pp.73.4.874

Lloret, P. G., and Casero, P. J. (2002). "Lateral root initiation," in Plant Roots: The Hidden Half, 3rd Edn, eds Y. Waisel, A. Eshel, and U. Kafkafi (New York, NY: Marcel Dekker, Inc.), 127-155. doi: 10.1201/9780203909423.ch8

Lloret, P. G., Casero, P. J., Navascués, J., and Pulgarín, A. (1988). The effects of removal of the root tip on lateral root distribution in adventitious roots of onion. New Phytol. 110, 143-149. doi: 10.1111/j.1469-8137.1988.tb00247.x

Lloret, P. G., and Pulgarín, A. (1992). Effect of naphthaleneacetic acid on the formation of lateral roots in the adventitious root of Allium cepa: number and arrangement of laterals along the parent root. Can. J. Bot. 70, 1891-1896. doi: 10.1139/b92-234

Lloret, P. G., Vidal, M. R., Casero, P. J., and Navascués, J. (1985). The relationship between lateral-root distribution and endodermis and pericycle cell length in Allium cepa L. adventitious roots. Ann. Bot. 56, 189-195. doi: 10.1093/ oxfordjournals.aob.a087002

Löfke, C., Dünser, K., Scheuring, D., and Kleine-Vehn, J. (2015). Auxin regulates SNARE-dependent vacuolar morphology restricting cell size. eLife 4:5868. doi: $10.7554 /$ eLife. 05868

Lomax, T. L., Muday, G. K., and Rubery, P. H. (1995). “Auxin transport," in Plant Hormones: Physiology, Biochemistry and Molecular Biology, ed. P. J. Davies (Dordrecht: Kluwer), 509-530. doi: 10.1007/978-94-0110473-9_24

MacLeod, R. D. (1990). Lateral root primordium inception in Zea mays L. Environ. Exp. Bot. 30, 225-234. doi: 10.1016/0098-8472(90)90068-F

Menke, F. L. H., and Scheres, B. (2009). Plant asymmetric cell division, Vive la difference! Cell 137, 1189-1192. doi: 10.1016/j.cell.2009.06.007

Mitchell, E. K., and Davies, P. J. (1975). Evidence for three different systems of movement of indoleacetic acid in intact roots of Phaseolus coccineus. Physiol. Plant. 33, 290-294. doi: 10.1111/j.1399-3054.1975.tb03171.x

Muday, G. K., and DeLong, A. (2001). Polar auxin transport: controlling where and how much. Trends Plant Sci. 6, 535-542. doi: 10.1016/S1360-1385(01)02101-X

Muday, G. K., and Haworth, P. (1994). Tomato root growth, gravitropism, and lateral development: correlation with auxin transport. Plant Physiol. Biochem. 32, 193-203.

Nieuwland, J., Maughan, S., Dewitte, W., Scofield, S., Sanz, L., and Murray, J. A. H. (2009). The D-type cyclin CYCD4;1 modulates lateral root density in Arabidopsis by affecting the basal meristem region. Proc. Natl. Acad. Sci. U.S.A. 106, 22528-22533. doi: 10.1073/pnas.0906354106

Ohwaki, Y., and Tsurumi, S. (1976). Auxin transport and growth in intact roots of Vicia faba. Plant Cell Physiol. 17, 1329-1342.

Pierik, R., Tholen, D., Poorter, H., Visser, E. J. W., and Voesenek, L. A. C. J. (2006). The janus face of ethylene: growth inhibition and stimulation. Trends Plant Sci. 11, 176-183. doi: 10.1016/j.tplants.2006.02.006

Pulgarín, A., Navascués, J., Casero, P. J., and Lloret, P. G. (1988). Branching pattern in onion adventitious roots. Am. J. Bot. 75, 425-432. doi: 10.1111/j.1469-8137. 1989.tb00347.x

Rashotte, A. M., Brady, S. R., Reed, R. C., Ante, S. J., and Muday, G. K. (2000). Basipetal auxin transport is required for gravitropism in roots of arabidopsis. Plant Physiol. 122, 481-490. doi: 10.1104/pp.122.2.481

Rashotte, A. M., Delong, A., and Muday, G. K. (2001). Genetic and chemical reductions in protein phosphatase activity alter auxin transport, gravity response, and lateral root growth. Plant Cell 13, 1683-1697. doi: 10.1105/tpc. 13.7.1683

Reed, R. C., Brady, S. R., and Muday, G. K. (1998). Inhibition of auxin movement from the shoot into the root inhibits lateral root development in Arabidopsis. Plant Physiol. 118, 1369-1378. doi: 10.1104/pp.118.4.1369

Rioboo, C., O'connor, J. E., Prado, R., Herrero, C., and Cid, A. (2009). Cell proliferation alterations in chlorella cells under stress conditions. Aquat. Toxicol. 94, 229-237. doi: 10.1016/j.aquatox.2009.07.009

Ruzicka, K., Ljung, K., Vanneste, S., Podhorská, R., Beeckman, T., Firml, J., et al. (2007). Ethylene regulates root growth through effects on auxin biosynthesis and transport-dependent auxin distribution. Plant Cell 19, 2197-2212. doi: 10.1105/tpc.107.052126

Tsurumi, S., and Ohwaki, Y. (1978). Transport of 14C-labeled indoleacetic acid in Vicia faba root segments. Plant Cell Physiol. 19, 1195-1206.

Varney, G. T., Canny, M. J., Wang, X. L., and Mccully, M. E. (1991). The branch roots of Zea. I. First order branches, their number, sizes and division into classes. Ann. Bot. 67, 357-364. doi: 10.1093/oxfordjournals.aob.a088203

Walker, D. J., Black, C. R., and Miller, A. J. (1998). The role of cytosolic potassium and $\mathrm{pH}$ in the growth of barley roots. Plant Physiol. 118, 957-964. doi: 10.1104/ pp.118.3.957

Zeadan, S. M., and Macleod, R. D. (1984). Some effects of indol-3-yl-acetic acid on lateral root development in attached and excised roots of Pisum sativum L. Ann. Bot. 54, 759-766. doi: 10.1093/oxfordjournals.aob.a086848

Zhang, N. G., and Hasenstein, K. H. (1999). Initiation and elongation of lateral roots in Lactuca sativa. Int. J. Plant Sci. 160, 511-519. doi: 10.1086/314147

Conflict of Interest Statement: The authors declare that the research was conducted in the absence of any commercial or financial relationships that could be construed as a potential conflict of interest.

Copyright (c) 2019 Alarcón, Salguero and Lloret. This is an open-access article distributed under the terms of the Creative Commons Attribution License (CC BY). The use, distribution or reproduction in other forums is permitted, provided the original author(s) and the copyright owner(s) are credited and that the original publication in this journal is cited, in accordance with accepted academic practice. No use, distribution or reproduction is permitted which does not comply with these terms. 